\title{
Kajian Penerapan Multi Lane Fee Flow (Mlff) Di Jalan Tol Indonesia
}

\author{
Anton Budiharjo, Sekar Ratri Margarani \\ ${ }^{1}$ Dosen$^{2}$ Mahasiswa, Program Studi Manajemen Keselamatan \\ Transportasi Jalan, \\ Politeknik Keselamatan Transportasi Jalan \\ Email : anton@pktj.ac.id
}

\begin{abstract}
The increasing number of transportation is not in line with the road construction growth in Indonesia. Mix traffic and congestion are often found especially in urban areas. Toll roads are made to reduce congestion level that occurs. Nowadays, Indonesia applies the toll payments by using electronic cards which in fact still causes the queue of vehicles to transact at toll gates. Technology updates are needed, and that is by using Multi Lane Free Flow. It is a payment method without stopping in which the users do not need to stop their vehicles to transact. In this study, we will discuss the analysis of Multi Lane Free Flow application when it is applied in Indonesia using the PEST analysis and SWOT analysis method. From the results of the PEST analysis and SWOT analysis, it can be said that Multi Lane Free Flow is decent enough to be applied in Indonesia by selecting the right and appropriate technology and also suitable with the culture of Indonesian citizen.
\end{abstract}

Key Words : Queue, Delay, Transactions, Multi Lane Free Flow

\begin{abstract}
Abstrak
Jumlah kendaraan yang terus meningkat tidak sejalan dengan pertumbuhan pembangunan jalan di Indonesia. Mix traffic dan kemacetan sering ditemui terutama di daerah perkotaan. Jalan tol dibuat untuk mengurangi tingkat kemacetan yang terjadi. Saat ini Indonesia menerapkan pembayaran menggunakan kartu elektronik yang pada kenyatannya masih menyebabkan antrian kendaraan untuk bertransaksi di gerbang tol. Diperlukan adanya pembaruan teknologi yaitu menggunakan Multi Lane Free Flow. Yaitu metode pembayaran tanpa berhenti dengan pengguna tidak harus menghentikan kendaraannya untuk bertransaksi. Pada penelitian kali ini akan dibahas mengenai analisis penerapan Multi Lane Free Flow bila diterapkan di Indonesia menggunakan metode analisis PEST dan analisis SWOT. Dari hasil analisis PEST dan analisis SWOT dapat dikatakan bahwa Multi Lane Free Flow layak untuk diterapkan di Indonesia dengan pemilihan teknologi yang tepat dan sesuai dengan culture dari masyarakat Indonesia.
\end{abstract}

Kata Kunci : Antrian, Tundaan, Transaksi, Multi Lane Free Flow

\section{A. PENDAHULUAN}

Jumlah kendaraan yang ada di Indonesia saat ini terus meningkat. Hal ini tidak sejalan dengan pertumbuhan pembangunan jalan dikarenakan lahan yang sudah tidak memadai. Kendaraan yang ada di jalan mengalami mix traffic dari sepeda motor, kendaraan ringan, kendaraan berat maupun kendaraan tidak bermotor. Kemacetan sudah pasti sering terjadi di jalan terutama di daerah perkotaan. Waktu tempuh akan semakin bertambah karena hambatan yang ada di jalan. Dengan adanya hal tersebut dibuatlah jalan bebas hambatan atau yang biasa disebut dengan jalan tol. Menurut Peraturan Pemerintah Republik Indonesia Nomor 15 tahun 2005 tentang Jalan Tol, jalan tol adalah jalan umum yang merupakan bagian sistem jaringan jalan dan sebagai jalan nasional yang penggunaannya diwajibkan membayar tol. Tol sendiri berarti sejumlah uang tertentu yang dibayarkan untuk penggunaan jalan tol. Jalan tol dikelola oleh suatu lembaga khusus yang dinamakan Badan Pengatur Jalan Tol. Badan Pengatur Jalan Tol yang selanjutnya disebut BPJT adalah badan yang dibentuk oleh Menteri, ada di bawah, 
dan bertanggung jawab kepada Menteri. Jalan tol diselenggarakan untuk mewujudkan pemerataan pembangunan dan hasil-hasilnya serta keseimbangan dalam pengembangan wilayah dengan memperhatikan keadilan, yang dapat dicapai dengan membina jaringan jalan yang dananya berasal dari pengguna jalan. Jalan tol bertujuan untuk meningkatkan efisiensi pelayanan jasa distribusi guna menunjang peningkatan pertumbuhan ekonomi terutama di wilayah yang sudah tinggi tingkat perkembangannya.

Untuk dapat menggunakan jalan tol, pengguna harus membayarkan sejumlah uang tertentu yang saat ini di Indonesia telah diterapkan transaksi E-Tol. Dimana pengguna jasa jalan tol perlu untuk menempelkan kartu yang berisi saldo yang nantinya akan berkurang sesuai dengan tarif tol yang sudah ditentukan di setiap jalan tol. Pada saat lalu lintas padat, gerbang tol mengalami antrian kendaraan yang melakukan pembayaran untuk memasuki jalan tol. Diperlukan waktu untuk setiap kendaraan dalam melakukan pembayaran yang menyebabkan antrian, dan terkadang ada beberapa pengendara masih mengalami kesulitan untuk menge-tap kartu. Sebagai contoh yang terjadi di jalan tol Cawang-Tomang-Cengkareng pada tahun 2018 volume lalu lintas mencapai 204 juta kendaraan dalam satu tahun dengan rata-rata kecepatan kendaraannya adalah $65,3 \mathrm{~km} / \mathrm{jam}$. Kecepatan transaksi rata-rata pada setiap gerbang tol adalah 3,09 detik dengan panjang antrian rata-rata 5 kendaraan pada masing-masing gerbang tol.

Dengan meningkatnya ilmu pengetahuan teknologi, saat ini mulai dikembangkan suatu alat transaksi yang disebut dengan Multi Lane Free Flow. Multi Lane Free Flow atau MLFF adalah suatu metode pembayaran tol tanpa berhenti dengan pengguna tidak harus menghentikan kendaraannya di gerbang tol. Awalnya sistem ini direncanakan diterapkan di Indonesia pada akhir tahun 2018. Namun pelaksanaanya terhambat dikarenakan belum dilakukannya pelelangan teknologi apa yang cocok untuk diterapkan di Indonesia. Oleh karena itu penulis akan membahas mengenai Multi Lane Free Flow dan bagaimana penerapannya di negara lain.

Berdasarkan pendahuluan diatas, penulis tertarik untuk melakukan penelitian yang berisi kajian mengenai Multi Lane Free Flow. dari latar belakang tersebut, maka didapatkan rumusan masalah yaitu:

1. Apakah permasalahan yang ada dalam sistem transaksi pembayaran tol di Indonesia?

2. Apakah Multi Lane Free Flow dapat diterapkan di jalan tol yang ada di Indonesia? Berdasarkan rumusan masalah dalam penelitian ini, maka tujuan dari penelitian ini adalah:

1. Untuk mengetahui permasalahan apakah yang ada dalam sistem transaksi pembayaran tol di Indonesia.

2. Untuk mengetahui apakah Multi Lane Free Flow dapat diterapkan di jalan tol yang ada di Indonesia

\section{B. METODE PENELITIAN}

Tahapan dalam penelitian kali ini dapat dilihat pada bagan alir berikut ini. 


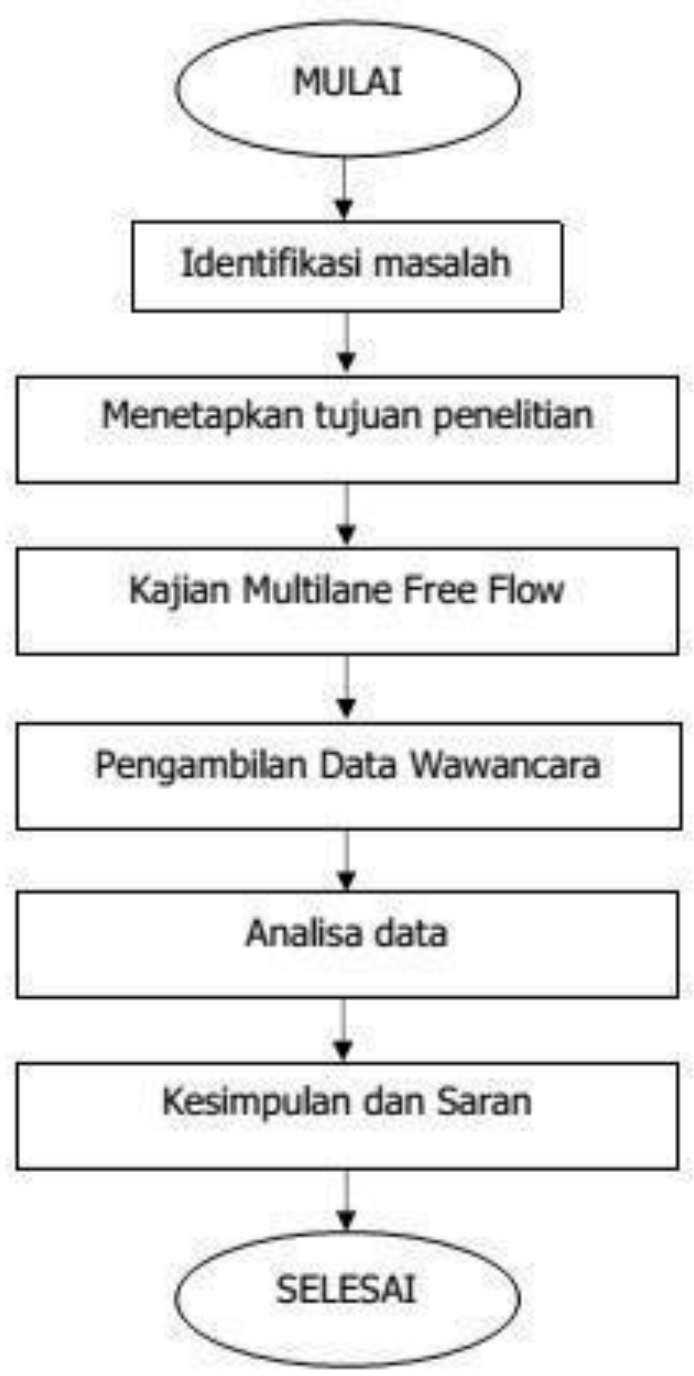

Penelitian kali ini dimulai dengan mengidentifikasi terhadap permasalahan yang terkait dengan penerapan Multi Lane Free Flow di Indonesia yang penerapannya masih tertunda hingga saat ini. Kemudian kemudian dilakukan peru,usan masalah dan menetapkan tujuan penelitian mengenai penerapan Multi Lane Free Flow di Indonesia.

Teknik pengumpulan data yang dilakukan dalam penelitian digunakan studi literature dan wawancara yang terkait dengan penerapan Multi Lane Free Flow dan metode-metode pembayaran yang diterapkan di jalan tol yang ada di Indonesia. Data-data yang dikumpulkan tersebut dapat diperoleh dengan cara mengumpulkan literature/referensi dari berbagai sumber yang terpercaya baik dari dalam negeri maupun dari luar negeri. Referensi yang dimaksud diantaranya adalah jurnal ilmiah, artikel, buku, laporan penelitian, dan lain-lain. Untuk wawancara dilakukan kepada pihak terkait dalam hal ini adalah Badan Pengatur Jalan Tol. Analisis data dilakukan dengan metode kualitatif. Sugiyono juga menyimpulkan bahwa metode penelitian kualitatif adalah metode penelitian yang berlandaskan pada filsafat postpositivisme, digunakan untuk meneliti pada kondisi obyek yang alamiah, dimana peneliti adalah sebagai instrument kunci, pengambilan sampel sumber data dilakukan secara purposive dan snowball teknik pengumpulan dengan trianggulasi (gabungan), analisis data bersifat induktif/kualitatif, dan hasil penelitian kualitatif lebih menekankan makna daripada generalisasi. Analisis dilakukan dengan metode analisis SWOT dan metode analisis PEST

\section{HASIL PENELITIAN DAN PEMBAHASAN}


A. Teknologi transaksi di jalan tol

Perkembengan transaksi jalan tol di Indonesia telah mengalami beberapa kali dan sedang dalam perkembangan, yaitu:

\section{Pay cash}

Pay cash adalah metode pembayaran yang dilakukan di gerbang tol dengan uang tunai. Metode ini mulai dikenalkan pada tahun 1987 saat pertama kali ada jalan tol di Indonesia. Pengguna jalan harus menyediakan sejumlah uang untuk membayar pada gerbang tol. Metode ini memerlukan waktu yang lama terutama apabila pengguna jalan tidak mempunyai uang pas.

\section{Electronic card}

Di Indonesia, per tanggal 31 Oktober 2017 seluruh pembayaran tol harus menggunakan kartu e-money. Pengguna jalan tidak perlu lagi menyiapkan uang tunai untuk pembayaran tol. Cukup menyediakan kartu elektronik yang berisi saldo untuk dapat menggunakan jalan tol. Kartu elektronik adalah kartu yang memiliki fungsi sebagai uang digital. Kartu ini termasuk dalam kartu prabayar yang memiliki nilai uang yang tersimpan secara elektronik dalam media server atau chip. Saldo dalam kartu adalah nilai uang yang tersimpan, dapat digunakan untuk beragam pembayaran di toko yang menerima pembayaran dengan emoney.

\section{Single lane free flow (SLFF)}

Single lane Free Flow adalah sistem pembayaran tapa henti dalam setiap lajur transaksi. Sistem ini memungkinkan kendaraan untuk tidak perlu lagi menghentikan kendaraan di gerbang tol untuk melakukan tapping transaksi. Dengan adanya sistem ini diharapkan dapat mencegah penumpukan antrian transaksi di gerbang tol. Waktu tempuh juga lebih cepat karena kendaraan tidak perlu lagi berhenti dan melakukan antrian untuk bertransaksi di gerbang tol. Namun untuk SLFF hanya ada satu lajur yang menggunakan sistem free flow. 


\section{Gambar 1. Single Lane Free Flow (SLFF)}

Sumber : $\underline{\text { www.ydttech.com }}(2019)$

Di Indonesia, badan usaha jalan tol yang sudah melakukan uji coba Single Lane Free Flow adalah PT. Jasa Marga dengan berbasis RFID (Radio Frequency Identification) di gerbang tol Cengkareng dan Kapuk.

Selain Jasa Marga, pada bulan Maret 2019 PT Marga Mandala Sakti selaku operator tol Tangerang-Merak menerapkan teknologi SLFF menggunakan sistem Dedicated Short Range Communication (DSRC), yang memungkinkan penyimpanan data atau identitas kendaraan dalam sebuah alat yang diletakkan di kendaraan atau on board unit.

4. Multi lane free flow

Multi Lane Free Flow sebagai bentuk dari ETC adalah suatu metode baru dalam pembayaran tol dimana kendaraan tidak perlu berhenti dan menghentikan kendaraannya di gerbang tol. Sistem yang ada mengidentifikasi kendaraan sehingga kendaraan dapat terus melajukan kendaraan dengan kecepatan tinggi. 


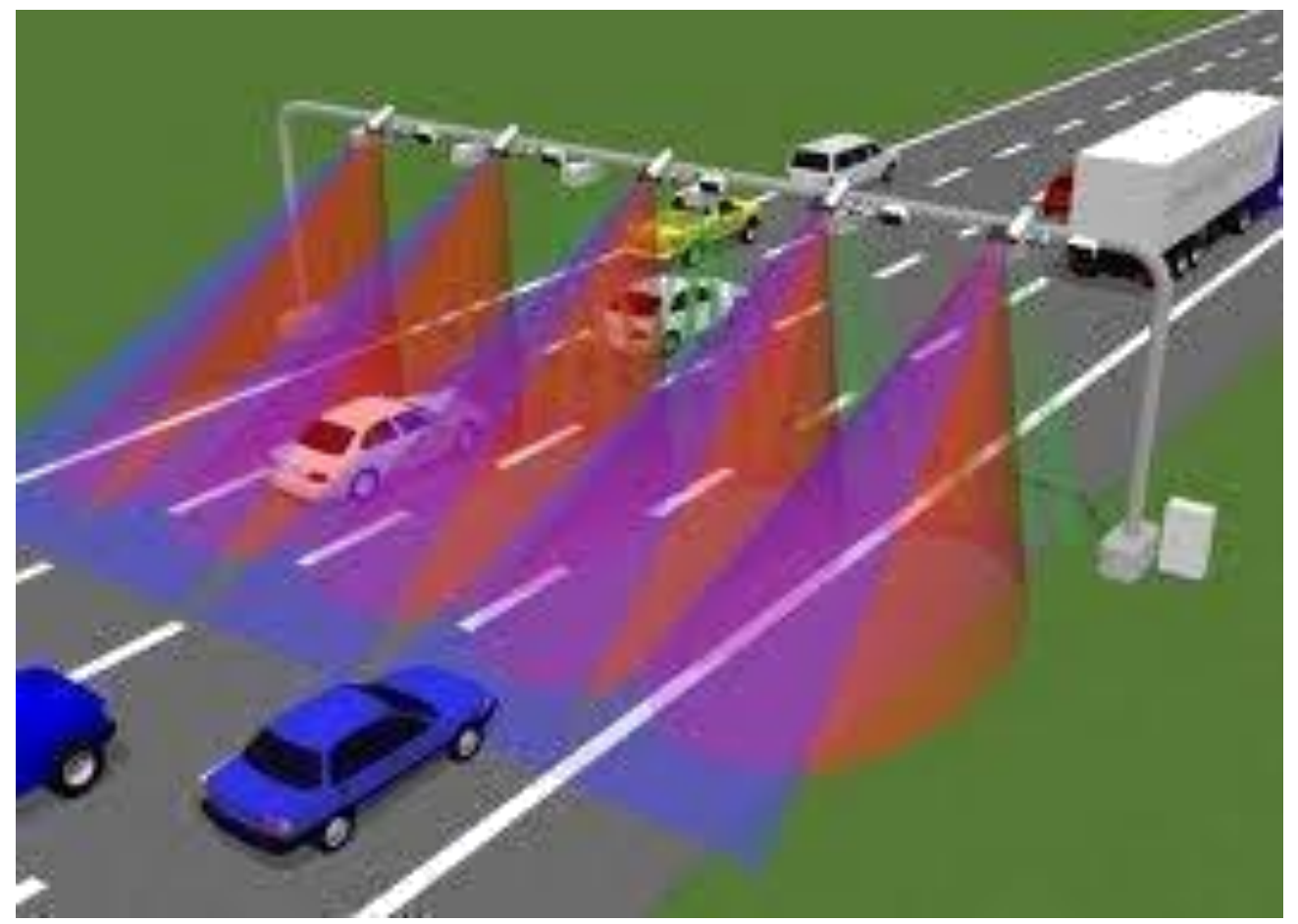

\section{Gambar 2. Multi Lane Free Flow}

Sumber : $\underline{\text { www.id.quora.com }}$ (2019)

Multi Lane Free Flow memiliki fungsi yaitu :

1) Dapat mendeteksi kendaraan yang melewati gerbang tol

2) Sistem memproses informasi transaksi ke manajemen untuk proses transaksi

3) Pengawasan dan pemantauan status dan aktifitas pada gerbang tol

4) Melindungi data agar tidak terjadi manipulasi data maupun data dapat hilang

Multi Lane Free Flow memiliki banyak kelebihan dibandingkan dengan metode pembayaran yang lain. Waktu tempuh dapat dilakukan lebih cepat dan efisien, tidak terjadi antrian dan tundaan di gerbang tol, ramah lingkungan dan dapat mempercepat mobilitas pengiriman barang dan jasa.

Gagasan mengenai Multi Lane Free Flow di Indonesia mulai muncul sekitar tahun 2017. Pada tanggal 2 Oktober 2017, Indonesia mendapat kunjungan dari Pemerintah Hungaria. Menteri Pembangunan Nasional Hungaria, Dr. Miklos Sesztak yang didampingi oleh Duta Besar Hungaria untuk Indonesia yaitu Judith Nemeth Pach dan Sekretaris Kedubes Hungaria, melakukan pertemuan dengan Menteri Pekerjaan Umum dan Perumahan Rakyat, Basuki Hadimuljono di kantor Kementerian Pekerjaan Umum dan Perumahan Rakyat di Jakarta. Dalam pertemuan tersebut, salah satu hal yang dibahas adalah mengenai Multi Lane Free Flow. Hungaria memberikan dukungan dalam hal teknolongi Multi Lane Free Flow di gerbang tol. 
B. Komparasi teknologi transaksi tol

Terdapat beberapa pilihan jenis teknologi yang memungkinkan diterapkan untuk Multi Lane Free Flow di Indonesia. Dalam pemilihan teknologi untuk Multi Lane Free Flow memerlukan pertimbangan antara lain kehandalan dari teknologi yang akan dipilih, seberapa akurat dari alat yang dipasang dapat mendeteksi data kendaraan yang melewatinya. Biaya investasi harus diperhitungkan agar badan usaha dan pemangku kepentingan lain juga tidak mengalami kerugian dalam berinvestasi. Selain itu baik dari Badan Pengatur Jalan Tol maupun badan usaha perlu mempertimbangkan kemampuan dari pengguna yang akan menggunakan jalan tol, bila pengendara diberatkan oleh teknologi yang akan dipilih maka bisa saja terjadi masyarakat tidak lagi memilih jalan tol untuk perjalanannya. Alternatif teknologi yang dapat digunakan adalah ANPR, DSRC, RFID, dan GNSS.

\section{ANPR}

ANPR atau Automatic Number Plate Recognition adalah salah satu metode yang diandalkan untuk identifikasi kendaraan di era saat ini. Metode yang digunakan sebagai pengawasan kendaraan yang menggunakan pengenalan karakter optik pada gambar dengan membaca plat nomor kendaraan. Pengenalan plat nomor dapat menggunakan CCTV yang diletak di daerah lalu lintas atau daerah khusus yang dirancang untuk tugas tertentu.

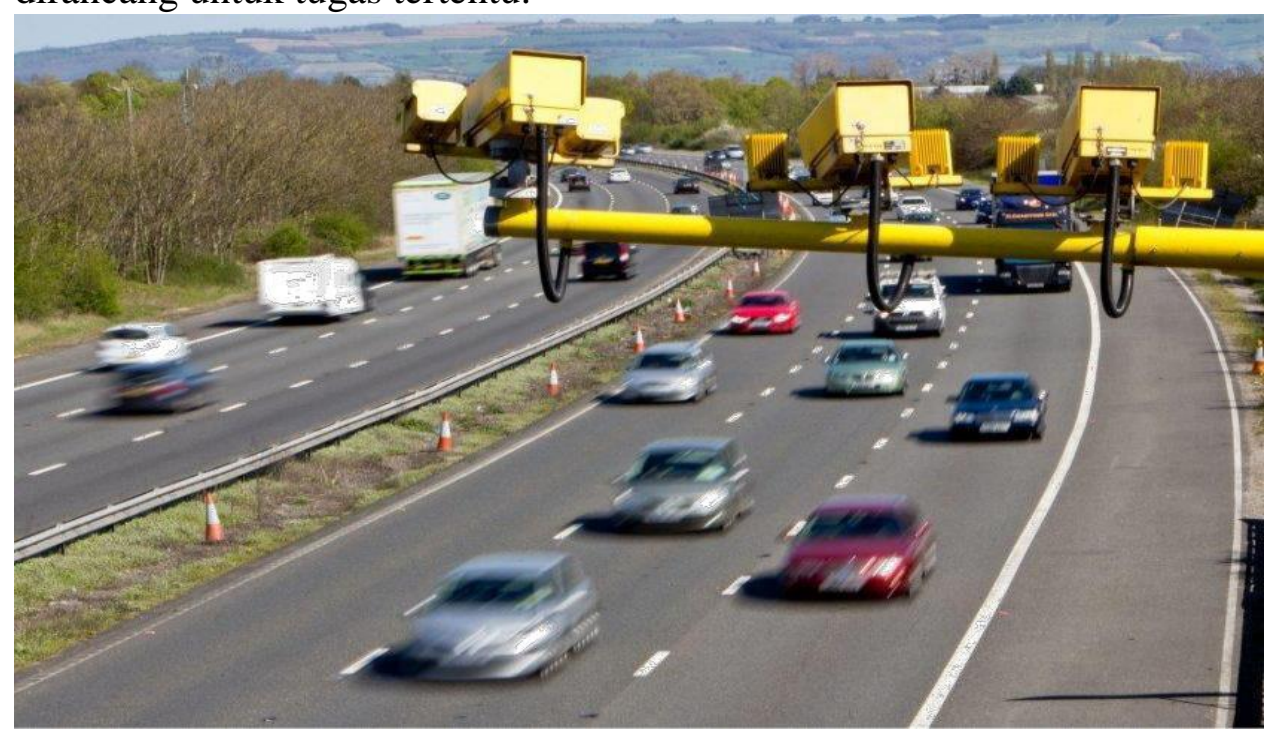

\section{Gambar 3. Kamera ANPR}

Sumber : www.rivervaleleasing.co.uk (2019) 


\section{DSRC}

DSRC atau Dedicated Short Range Communication adalah saluran komunikasi nirkabel satu arah atau dua arah jarak pendek sampai jarak menengah yang dirancang khusus untuk penggunaan otomotif yang memungkinkan transmisi data yang sangat tinggi. Ini sangat penting dalam aplikasi keselamatan aktif berbasis komunikasi untuk mencegah kecelakaan.

Ada dua jenis DSRC yaitu vehicle-to-vehicle dan vehicle-toinfrastructure. Keduanya membutuhkan konstanta wireless interface yang terlindungi dalam penundaan waktu yang singkat dan kondisi cuaca yang ekstrem, yang semuanya diaktifkan oleh DSRC. Teknologi DSRC membutuhkan OBU sebagai penyimpan identitas dari pengguna jalan dan beberapa informasi lain yang terkait.

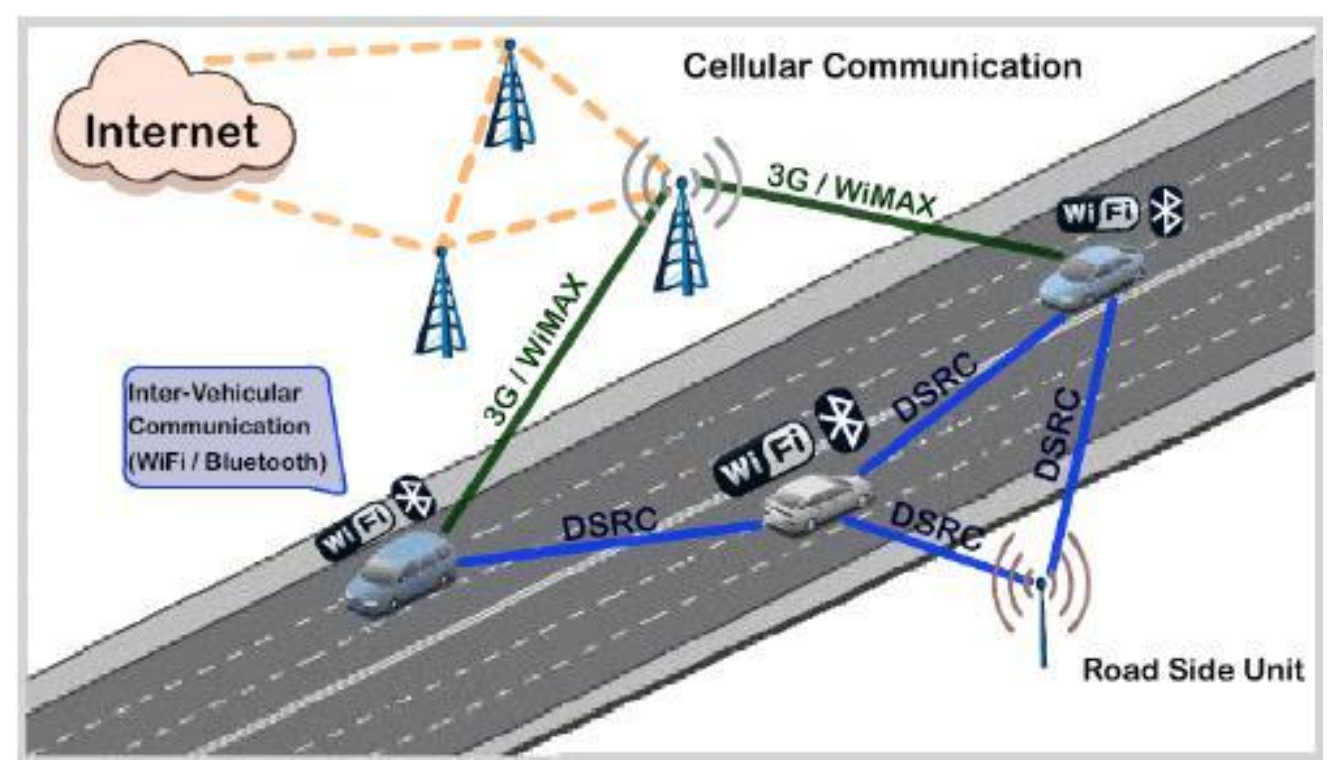

Gambar 4. Sistem DSRC

Sumber : www.researchgate.net (2019)

3. GNSS

GNSS atau Global Navigation Satelite System adalah konstelasi satelit yang menyediakan sinyal dari ruang angkasa yang mentrasmisikan data penentuan posisi dan waktu ke penerima GNSS. Penerima ini kemudian menggunakan data ini untuk menentukan lokasi mereka. 


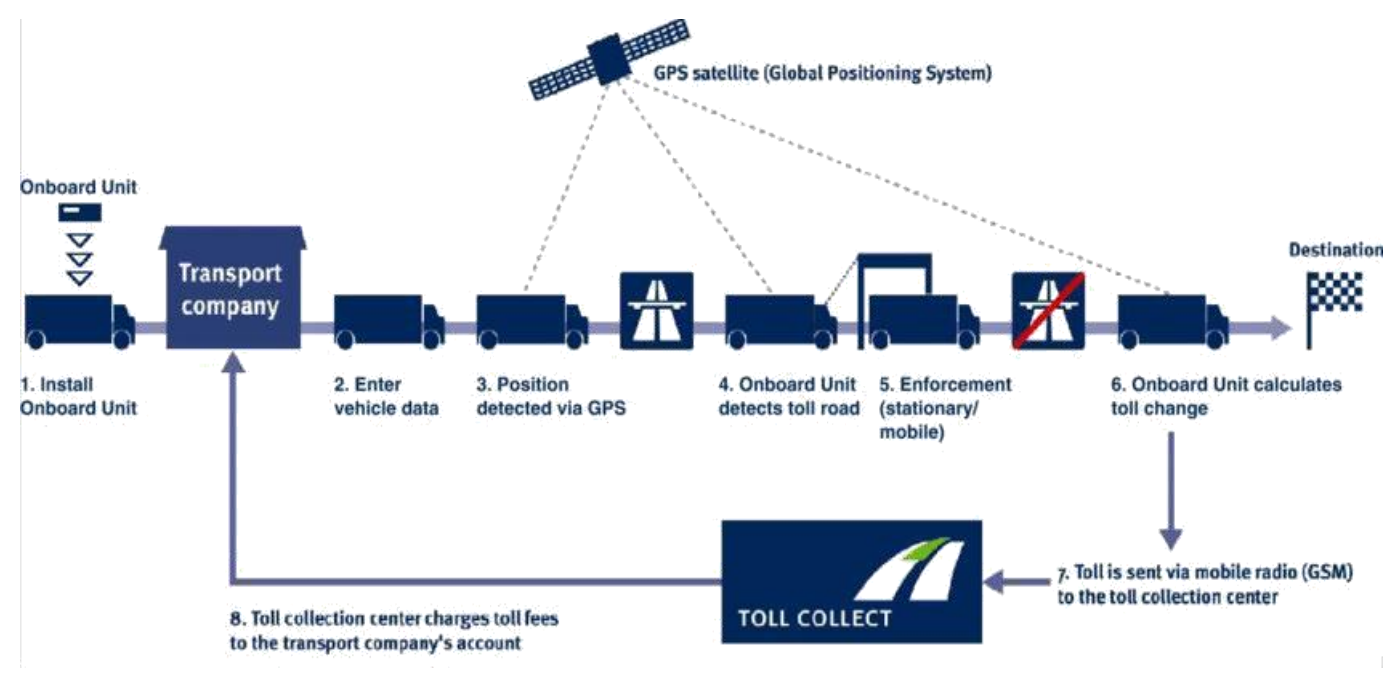

Gambar 5. Sistem GNSS

Sumber : www.researchgate.net (2019)

\section{RFID}

RFID atau Radio Frequency Identification adalah sistem identifikasi berbasis wireless yang memungkinkan pengambilan data tanpa harus bersentuhan seperti barcode atau magnetic card. Alat ini menggunakan sistem radiasi elektromagnetik untuk mengirimkan kode. RFID menggunakan sistem identifikasi dengan gelombang radio, karena minimal dibutuhkan dua buah perangkat agar alat ini dapat berfungsi, adapun perangkat yang dibutuhkan disebut Tag dan Reader. Tag RFID adalah alat yang melekat pada objek yang akan diidentifikasi oleh RFID Reader.

Single Lane Free Flow sudah mulai diuji coba di beberapa tol di Indonesia. Teknologi yang digunakan adalah RFID dan DSRC. Biaya yang dikeluarkan oleh pengguna juga tidak terlalu besar. Namun masih menjadi kajian mengenai teknologi apa yang dipilih untuk diterapkan di Indonesia. 


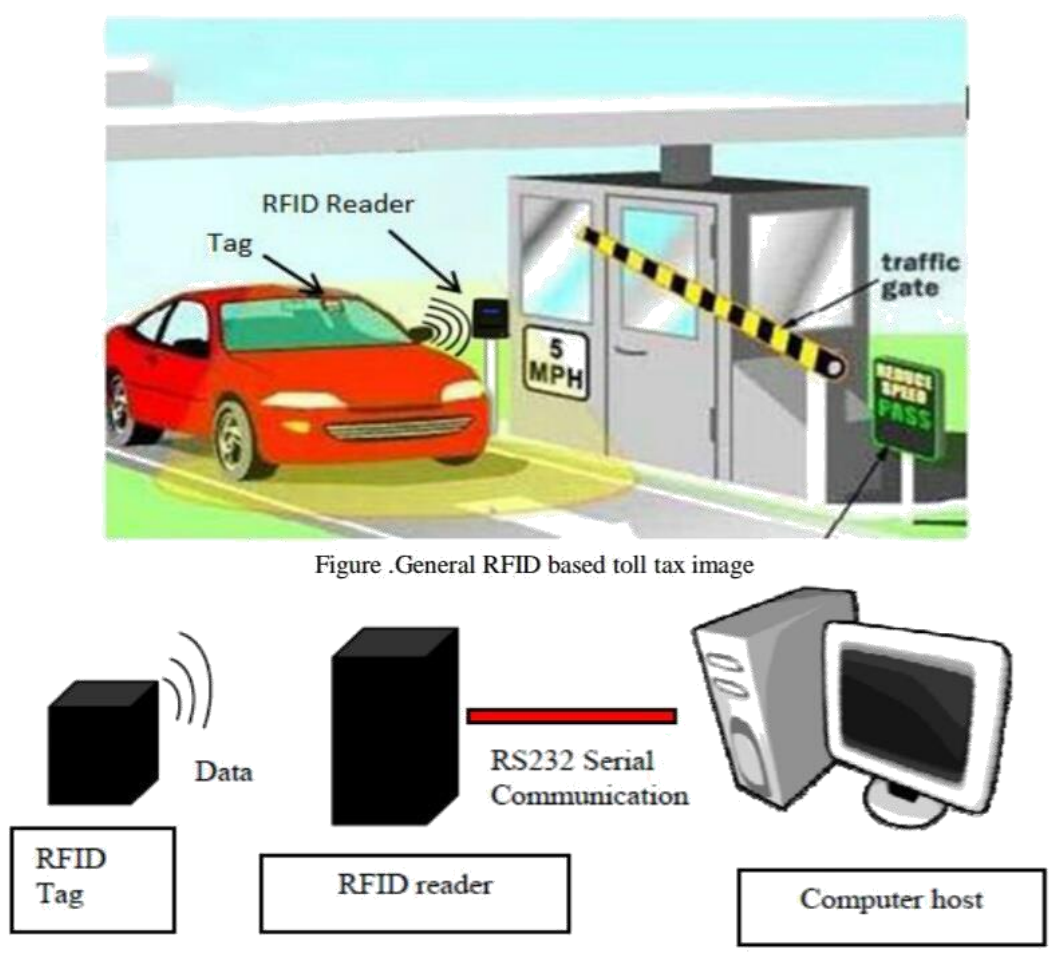

Gambar 5. Sistem RFID

Sumber : www.transmitter.ieee.org (2019)

\section{Analisis PEST}

Analisis PEST adalah analisis terhadap faktor lingkungan eksternal bisnis yang meliputi bidang politik, ekonomi, sosial dan teknologi. Arah dari analisis PEST adalah kerangka untuk menilai sebuah situasi, dan menilai strategi atau posisi, arah perusahaan, rencana pemasaran atau ide. Dimana analisis ini dapat diambil suatu peluang atau ancaman baru bagi perusahaan.

\section{Faktor Politik}

Dapat dikatakan bahwa pasca pemilu 2019 memberikan dampak positif bagi pasar modal sehingga para investor juga mencari tahu peluang- peluang investasi dan arah-arah kebijakan atau terobosan dan gagasan baru yang dapat diantisipasi di tahun pemerintahan ini.

\section{Faktor ekonomi}

Dalam pengoperasiannya setiap badan usaha jalan tol memiliki rencana usaha dan tarif tersendiri. Pengumpulan tol juga dilakukan oleh masingmasing badan usaha jalan tol. Dengan adanya Multi Lane Free Flow pengumpulan tol akan dijadikan dalam satu organisasi tersendiri dimana organisasi tersebut yang akan melakukan pembagian pengumpulan tol pada masing-masing badan usaha jalan tol.

3. Faktor sosial 
Dengan adanya teknologi baru untuk transaksi di jalan tol, perlu adanya pengenalan kepada masyarakat agar masyarakat dapat segera menyesuaikan dengan kondisi yang ada. Sosialisasi kepada masyarakat dapat dilakukan dengan talkshow, media cetak maupun elektronik. perlu adanya penegasan mengenai penegakan hukum dan resiko yang dapat timbul. Hal lain yang perlu dilakukan adalah dari badan pengatur jalan tol juga perlu melakukan survei kepada pengguna jalan mengenai bagaimana pendapat dari pengguna jalan mengenai penerapan teknologi ini.

4. Faktor teknologi

Banyaknya jumlah kendaraan di Indonesia saat ini, dibutuhkan data yang jelas mengenai kepemilikan kendaraan. Pada kenyataannya masyarakat tidak hanya membeli kendaraan yang memiliki kondisi yang baru, tapi juga banyak masyarakat membeli kendaraan dalam kondisi bekas. Pada saat membeli mobil bekas pemilik yang baru belum tentu langsung melakukan balik nama kepemilikan kendaraan. Masih banyak pemilik kendaraan yang menggunakan nama pemilik lama untuk melakukan perpanjangan surat tanda nomor kendaraan. Saat kendaraan yang melewati Multi Lane Free Flow, akan terpancar sinyal dari multi lane ke kendaraan yang melewati melalui on board unit, RFID, atau teknologi lain yang terpasang pada kendaraan. Benda tersebut akan menyimpan data base pengguna jalan. Apabila data dari pengguna jalan yang terdapat pada unit yang ada pada kendaraan tidak terbaca, multi lane memiliki back up kamera yang dapat membaca dan mendeteksi plat nomor kendaraan, jenis kendaraan, dimensi kendaraan dan pemilik kendaraan yang lewat tersebut yang nantinya akan dikenakan tanggungan biaya jalan tol.

\section{A. Analisis SWOT}

Analisis SWOT adalah suatu metode perencanaan strategis untuk mengevaluasi faktor-faktor yang berpengaruh dalam usaha mencapai tujuan, yaitu kekuatan (Strengths), kekuatan (Weaknesses), peluang (Opportunities), dan ancaman (Threats), baik itu tujuan jangka pendek maupun jangka panjang. Metode analisis ini tujuannya adalah untuk mengambarkan situasi dan kondisi yang sedang dihadapi dan bukan merupakan alat analisis yang dapat memberikan solusi terhadap masalah yang tengah dihadapi.

1. Strength

Dengan adanya teknologi Multi Lane Free Flow memberikan banyak dampak positif kepada masyarakat. Mobilitas pengiriman barang dan jasa dapat terlaksana dengan lebih cepat sehingga meningkatkan pendapatan bagi perusahaan. Antrian kendaraan yang melakukan transaksi di gerbang tol dapat dihilangkan karena pengguna tidak perlu lagi menghentikan kendaraan untuk melakukan transaksi. Tundaan waktu perjalanan bagi pengguna jalan dapat berkurang karena tidak ada lagi antrian kendaraan di gerbang tol. Kemacetan dapat terurai karena berkurangnya antrian kendaraan yang ada di gerbang tol.

\section{Weakness}


Perlu biaya yang besar untuk mengganti sistem transaksi yang ada, dan perlu diterapkan secara nasional. Selain itu pertimbangan dari teknologi yang cocok untuk diterapkan juga harus tepat. Penyamaan teknologi dilakukan untuk seluruh tol yang ada di Indonesia. Penyamaan teknologi ini dilakukan agar tidak memberatkan pengguna jalan untuk bertransaksi.

\section{Opportunities}

Dengan adanya pembaruan teknologi transaksi tol berupa Multi Lane Free Flow, dapat mendukung percepatan pembangunan nasional. Untuk para pelaku bisnis, dapat dilakukan pengembangan bisnis usaha berupa teknologi yang dipasang pada gantry maupun pada kendaraan.

4. Threats

Dengan teknologi MLFF nantinya sudah tidak ada lagi gerbang tol yang dipasang pada setiap jalan tol. Perilaku-perilaku menyimpang dari masyarakat mungkin saja terjadi, misalnya kendaraan yang tidak memiliki saldo dapat tetap masuk jalan tol ataupun kendaraan yang tidak memasang alat transaksi pada kendaraannya dapat masuk ke jalan tol. Hal ini akan menimbulkan kerugian bagi badan usaha jalan tol yang bersangkutan. Maka dari itu perlu adanya penegakan hukum yang jelas dan perlu dikaji lebih mendalam mengenai penerapan Multi Lane Free Flow melihat dari sisi culture masyarakat Indonesia.

\section{KESIMPULAN DAN SARAN}

A. Kesimpulan

1. Permasalahan yang ada dalam transaksi pembayaran jalan tol yang ada di Indonesia yang sering dikeluhkan oleh masyarakat adalah mengenai antrian kendaraan di gerbang tol. Dengan adanya antrian maka akan ada tundaan waktu perjalanan yang dialami oleh pengguna jalan.

2. Multi Lane Free Flow layak dan dapat diterapkan di Indonesia dilihat dari kelebihannya. Saat ini masih dilakukan kajian oleh pemerintah dalam hal ini adalah BPJT yang saat ini sedang bekerja sama dengan pihak dari Hungaria untuk melakukan pengkajian jalan tol di Indonesia. Namun, sampai saat ini juga belum ditentukan teknologi apa yang akan diterapkan karena perlu adanya pertimbangan dan adanya penyamaan teknologi di seluruh jalan tol di Indonesia.

B. Saran

1. Pemerintah agar bisa segera membuat sebuah badan yang menangani terkait penerbitan kartu single tol, mengingat penerapan MLFF dijalan tol hanya dibutuhkan satu kartu. Tidak seperti sekarang dengan GTO, masing-masing bank mengeluarkan produk kartu tol..

2. Pembuatan Standar Operasinal Pelaksanan yang jelas mengenai pengusahaan Multi Lane Free Flow dan pemasangannya agar dapat terorganisir dengan baik. 
3. Dilakukan pendataan yang jelas mengenai kepemilikan kendaraan agar tidak ada pihak yang dirugikan baik dari pengguna kendaraan maupun pemilik dari kendaraan.

4. Pemberian edukasi dan pengenalan teknologi kepada masyarakat agar masyarakat dapat segera menyesuaikan dengan perkembangan teknologi yang ada.

5. Adanya penelitian lanjutan dari penelitian sebelumnya yang lebih mendalam mengenai teknologi Multi Lane Free Flow.

\section{REFERENCES}

__, 2005. Peraturan Pemerintah Nomor 15 tahun 2005 Jalan Tol. Presiden Republik Indonesia.

Aleatica Labs. 2018. Multi-Lane Free-Flow tolling system (MLFF). Madrid.

Commission, European. 2016. Technology Options and Interoperability for Urban Vehicle Access Regulation (UVAR) Schemes. Eropa.

Eridani, D., Yuli C. Dan Imam Santoso. 2011. Simulasi Gerbang Tol Menggunakan RFID (Radio Frequency Identification). Semarang: TRANSMISI 13 (2). HU-GO, Electronic Toll System. About the Introduction of the System. www.hugo.hu.

Diakses pada 18 Juli 2019.

Its World Congress. 2017. The Progress \& Future Steps of Multi-Lane Free Flow Tolling.

Montreal.

Kementerian Pekerjaan Umum dan Perumahan Rakyat. 2017. Implementing Electronic Toll Collection In Indonesia Toll Road. Jakarta.

Nam, Na-kyung. 2014. Free Flow Multi Lane Smart Tolling System. Seoul. https://www.researchgate.net/figure/Wireless-networking-technology-in-V2V-and-V2Icommunication-DSRC-Dedicated-Short-Range_fig1_260398735 